\title{
Diagnosis of Rabies via RT-PCR on Skin Samples of Wild and Domestic Animals
}

\author{
Ulrike Zieger \\ School of Veterinary Medicine, St. George's University, St. George's, Grenada \\ Email: uzieger@sgu.edu
}

Received 18 August 2015; accepted 15 September 2015; published 18 September 2015

Copyright (C) 2015 by author and Scientific Research Publishing Inc.

This work is licensed under the Creative Commons Attribution International License (CC BY). http://creativecommons.org/licenses/by/4.0/

(c) (i) Open Access

\begin{abstract}
In developing countries, brain tissues from rabies suspect animals are not always available for diagnosis for a variety of reasons, such as lack of transport to submit a carcass or the difficulty of removing an animal's head or brain under field conditions. To enable diagnosis in such cases, there is a need for a reliable method, using an alternative non-neural tissue, which can be removed and submitted to the diagnostic laboratory without special training or equipment. In human medicine, skin is used successfully for the detection of rabies virus antigen using RT-PCR technology. Little work has been done in animals using RT-PCR on skin or extracted hair follicles. The current study was conducted in Grenada on skin from 36 wild and domestic animals, in which rabies virus infection had been confirmed in brain tissue via the direct fluorescent antibody (DFA) test, and in 31 negative control animals. RT-PCR on skin yielded a sensitivity of $97.2 \%(35 / 36)$ and a specificity of $100 \%(31 / 31)$. It is concluded that the examination of skin samples via RT-PCR provides a valuable diagnostic alternative in those cases where brain tissue is not readily available.
\end{abstract}

\section{Keywords}

Rabies Virus, Diagnosis, Skin, Animals, RT-PCR

\section{Introduction}

Rabies is a globally distributed infectious disease of the central nervous system of mammals, caused by members of the genus Lyssavirus in the family Rhabdoviridae. The rabies virus (RABV) is the type species of the genus Lyssavirus and causes most of the human rabies cases. Transmission typically occurs via the bite of an infected animal [1]. RABV antigen is detected in stained brain sections using the direct fluorescent antibody (DFA) test, which is the diagnostic gold standard [2] [3]. 
In Grenada, a small island in the Caribbean Sea, rabies is endemic. It is maintained in a wildlife host, the small Indian mongoose (Herpestes auropunctatus), with spillover into other animals or humans [4]-[7]. Unfortunately, many rabies suspects are never submitted and carcasses are burned or buried without laboratory confirmation. Reasons given include the lack of adequate transport, especially where livestock is involved, or the inaccessibility by car of the area where an animal has died, quick decomposition of a carcass in the tropical climate, or lack of expertise to safely remove the head or brain. At other times, brain removal is delayed leading to late diagnostic reporting.

To overcome some of the above limitations, it would be of advantage if even laymen could collect an easily accessible non-neural tissue without having to open or transport an entire carcass for the reliable diagnosis of rabies virus infection. RABV moves centripetally along nerves from the site of entry to the brain, where it multiplies and begins to cause clinical signs. Then, it moves centrifugally along nerves to peripheral tissues [8]. Among these tissues, saliva, tear fluid, or corneal impressions have been widely used [9], especially in human medicine, but viral shedding in these fluids is too inconsistent to give reliable results, unless taken as serial samples [10]. In contrast, examination of skin yielded very promising results: serial cryosections of skin from a variety of animals showed a sensitivity of $98 \%$ in the post-mortem rabies diagnosis using DFA when compared to the DFA test performed on brain tissue [11]. Limitations of using skin for DFA are that at least 20 sections need to be examined, the expensive equipment, and that decomposition renders tissues unsuitable for DFA testing. PCR can be used even on decomposed tissues, and a highly reliable PCR protocol was described using skin biopsies in human rabies cases [12]. Some data are available using PCR on animal skins [13]-[16], yet reports are not promising: For example, Wacharapluesadee et al. [13] examined extracted whisker follicles and hair follicles of dogs that had died of rabies in Thailand and concluded that sensitivities of 81.8\% using real-time PCR, and $66.7 \%$ using RT-PCR were “...not sufficient to help physicians (decide) whether to administer post exposure prophylaxis” in bite victims.

In the current study, we determined whether skin samples taken from animals after death and using conventional RT-PCR technology would be sufficiently sensitive in the diagnosis of RABV infection to serve as an easily obtainable alternative to brain tissue.

\section{Material and Methods}

\subsection{Animals}

A total of 36 confirmed rabid animals and 31 negative control animals were used. All cases had been submitted for rabies diagnosis to the Pathobiology Department, School of Veterinary Medicine, St. George’s University, Grenada, West Indies, between March 2011 and May 2015. Carcasses were processed within 24 hours of an animal's death, or when this was not possible, carcasses were kept at $-20^{\circ} \mathrm{C}$ until processing.

\subsection{Samples}

To reduce the potential risk of saliva contamination of the skin, carcasses were thoroughly cleaned under running water. A $2-4 \mathrm{~cm}^{2}$ section of skin was removed from the muzzle area, using a fresh sterile blade and taking care that the underlying muscle tissue or oral mucosa were not included. For a subset of animals, skin sections were also taken from the shoulder and hip area. All skin sections were individually stored dry at $-20^{\circ} \mathrm{C}$ in $50 \mathrm{~mL}$ plastic containers until processing. Sampling and processing of saliva and brain samples from these animals including total RNA extraction, RABV antigen detection using DFA, RT-PCR, real-time PCR and sequencing have been described [7].

\subsection{RNA Extraction}

For the extraction of total RNA, a skin sample was cut into sections of approximately $1 \mathrm{~mm}^{3}$ using fresh sterile blades. Care was taken to cut the skin at oblique angles to increase exposure of hair follicles. Excess hair and fat were cut off and removed. Total RNA was extracted from approximately $30 \mathrm{mg}$ of skin, using RNeasy Mini Kit spin column extraction (Qiagen GmbH, Hilden, Germany) following manufacturer's instructions. Skin was lysed in $0.6 \mathrm{~mL}$ RLT/beta-mercaptoethanol lysis buffer containing $1 \mathrm{~mm}$ zirconia/silica beads at a bead volume equal to skin volume (Biospec Products, Inc. Bartlesville, OK, USA), and milling samples in a beadbeater (Mini Beatbeater $^{\mathrm{TM}}$, Biospec Products) for $20 \mathrm{sec}$, resting for $60 \mathrm{sec}$, and milling again for 20 sec. Samples were cen- 
trifuged after lysis at 13,000 rpm for $3 \mathrm{~min}$ and $0.5 \mathrm{~mL}$ of the clear lysate was used in the spin column protocol. The final elution volume was $30 \mu \mathrm{L}$.

Total extracted RNA was measured using Nanodrop 2000 (Thermo Scientific, Waltham, MA, USA). The minimum concentration used in this study was $2.3 \mathrm{ng} \mathrm{RNA} / \mu \mathrm{L}$ and the maximum was $99.7 \mathrm{ng} \mathrm{RNA} / \mu \mathrm{L}$. Any sample containing more than $100 \mathrm{ng} \mathrm{RNA} / \mu \mathrm{L}$ was diluted to a final concentration of 40 - $50 \mathrm{ng} \mathrm{RNA} / \mu \mathrm{L}$. Samples, which contained less than $1 \mathrm{ng} \mathrm{RNA} / \mu \mathrm{L}$ or with a 260/280 ratio below 1.90 were discarded and the extraction repeated.

\subsection{RT-PCR}

RABV antigen was detected via RT-PCR as recently described [7]. Briefly, the one-step iScript protocol (Biorad Laboratories, Hercules, CA, USA) was used on 1 - $50 \mathrm{ng}$ total RNA per $25 \mu \mathrm{L}$ reaction mix. The primers used for amplification targeted a 110 bp fragment of the highly conserved region of the nucleoprotein (N)-gene: JW 12 (5'-ATGTAACACCYCTACAATG-3') and N 165-146 (5'-GCAGGGTAYTTRTACTCATA-3'). An Eppendorf Mastercycler ProS (Eppendorf AG, Hamburg, Germany) was used and RT-PCR products were visualized using $3 \%$ agarose gel electrophoresis and ethidium bromide staining.

\subsection{Statistical Methods}

Results obtained from the new method, i.e. RABV antigen detection in skin by RT-PCR, were compared to the gold standard of rabies diagnosis, the viral antigen detection in brain tissue by DFA. Sensitivity, specificity, Positive Predictive Value (PVP), Negative Predictive Value (NPV) and confidence limits at 95\% were calculated using MedCalc statistical software.

\section{Results}

Skin samples were taken from the muzzle area of 36 rabid animals and 31 negative controls. The animal species and numbers are listed in Table 1 . All cases had previously been confirmed as RABV positive, respectively negative, using DFA on brain tissue [7]. RT-PCR results from skin samples taken from the head are also presented in Table 1. In relation to the DFA test performed on brain tissue, the RT-PCR test performed on skin samples taken from the head of animals showed a sensitivity of $97.2 \%$ (95\%Cl: $85.47 \%-99.93 \%)$ and a specificity of 100\% (95\%Cl: 88.78\% - 100.00\%). The Positive Predictive Value (PVP) was 100\% (95\% Cl: 90.00\% 100.00\%) and the Negative Predictive Value (NPV) was 96.88 (95\% Cl: 83.78\% - 99.92\%).

Of the animals that tested RABV positive in skin taken from the head, only eight were also available for the collection of skin from their shoulder and hip areas: 3 dogs, 3 mongooses and 2 cats. In seven of these animals (87.5\%), RABV was detected in all three skin areas. In one dog, only the skin from the head tested RABV positive, whereas skin taken from the shoulder and hip areas were RABV negative.

Table 1. Comparison of RABV detection via RT-PCR in skin taken from the head to DFA in brain tissue in rabies-infected and uninfected animals.

\begin{tabular}{ccc}
\hline \multirow{2}{*}{ Animal species } & \multicolumn{2}{c}{ Numbers } \\
\cline { 2 - 3 } & RT-PCR positive (skin)/DFA positive (brain) & $\begin{array}{c}\text { RT-PCR negative (skin)/DFA } \\
\text { negative (brain) }\end{array}$ \\
\hline Mongoose (Herpestes auropunctatus) & $20 / 20[100 \%]$ & $5 / 5[100 \%]$ \\
Dog & $10 / 11[90.9 \%]$ & $17 / 17[100 \%]$ \\
Cat & $4 / 4[100 \%]$ & $3 / 3[100 \%]$ \\
Goat & $1 / 1[100 \%]$ & $1 / 1[100 \%]$ \\
Cow & - & $1 / 1[100 \%]$ \\
Bats & - & $3 / 3[100 \%]$ \\
(2 Glossophaga longirostris; & - & $1 / 1[100 \%]$ \\
1 Molossus molossus) & $\mathbf{3 1 / 3 1}[\mathbf{1 0 0 \% ]}$ \\
\hline
\end{tabular}


Testing skin for RABV antigen via spin column extraction and RT-PCR as described here took three hours from tissue lysis to gel visualization.

\section{Discussion}

The current study tested the use of RT-PCR on skin samples as an alternative to DFA testing on brain tissue for the post mortem diagnosis of rabies. Skin samples collected from animals’ heads showed a sensitivity of $97.2 \%$ and a specificity of $100 \%$ compared to the gold standard.

Skin as a potential non-neural tissue for rabies diagnosis has long been investigated. In human medicine, immunofluorescence (IF) techniques on skin biopsies typically taken from the nape of the neck have been successfully used in the post-mortem [17] and ante mortem rabies diagnosis [18] [19]. PCR technology has meanwhile replaced IF-staining of skin sections, and the collection of skin biopsies along with saliva and CSF samples and testing by PCR technology is now recommended as a routine measure in the ante-mortem diagnosis of rabies in humans [12] [20]-[23]. Indeed, Dacheux et al. [12] reported a sensitivity of 98\% using hemi-nested PCR applied to human skin and proposed to use skin as an alternative to brain DFA testing for the confirmation of rabies before and after death.

In veterinary medicine, IF techniques on skin specimens of rabid animals showed promising results [8] [11] [24]-[26], but were never routinely used, probably due to the expensive equipment needed for cryosectioning and the number of sections to be stained. Few reports are available which examine the use of skin using PCR techniques, possibly because the ante-mortem diagnosis is not as important in animals as in humans or because PCR with its inherent contamination issues has not been accepted as a primary method in rabies diagnosis. Wacharapluesadee et al. [13] concluded that their sensitivity of $81.8 \%$ using real-time PCR on extracted dog whisker follicles was insufficient. Studies conducted in India used skin from various animals before they died of rabies and detected RABV antigen in 9 of 13 (69\%) by RT-PC and in 11 of 13 (84\%) by real-time PCR [14] [15]. Kaw et al. [16] only observed a sensitivity of 57.1\% for ante-mortem skin samples using RT-PCR and 71.4\% using real-time PCR in animals.

It is interesting to note that the false negative case in the current study was a dog, which had died of paralytic rabies. Wacharapluesadee et al. [13] also found that most of their false-negative results originated from dogs that had died of paralytic rabies. Similarly, a high false-negative rate was reported for human paralytic cases when examining non-neural tissues [27]. This supports the idea that viral spread from the infected brain to peripheral tissues differs between paralytic and furious forms.

Considering the future possibility to use skin for ante-mortem diagnosis in animals, collection of biopsies from the head of a rabies suspect would only be safe under very tight physical restraint, with heavy sedation and/or brief anesthesia. Samples collected from the shoulder or hip area of an animal would be easier and safer to take. Although the sample size for comparing skin results was small $(n=8)$, the current study showed that RABV antigen could be detected in the skin of the head, shoulder and hip of a rabid animal. One of the 8 animals examined tested rabies positive using head skin, but had no detectable RABV antigen in its skin from the shoulder and hip regions. Contamination of the head skin with saliva in this case could be excluded, as its saliva tested RABV negative. The hair follicles of the head, lips, and especially whiskers are particularly well innervated [17], and being closest to the brain, it is reasonable to assume that the virus is detected here earlier and perhaps in higher numbers than elsewhere.

\section{Conclusion}

In the post-mortem diagnosis of rabies in animals, testing skin tissue via RT-PCR provides a highly sensitive and rapid alternative to the examination of brain tissue via DFA in those situations where brain is not readily available, or where the removal or examination of brain is delayed. The method described here may also be useful for the ante-mortem diagnosis of rabies during an animal's quarantine or clinical work-up stage.

\section{Acknowledgements}

The assistance of Dr. Alfred Chikweto and Dr. Keshaw Tiwari, SGU-SVM Grenada, in taking skin samples is greatly appreciated. The author is grateful to Dr. Ravindra Sharma, SGU-SVM, Grenada, and to Dr. Dirk Werling, RVC London, UK, for reviewing the manuscript. The support of St. Gorge's University via research grants 
$\# 10005$ and \#12015 is gratefully acknowledged.

\section{Competing Interests}

The author declares that there is no competing interest.

\section{References}

[1] Charlton, K.M. (1988) The Pathogenesis of Rabies. In: Campbell, J.M. and Charlton, K.M., Eds., Rabies. Kluwer Academic Publishers, Boston, 101-150. http://dx.doi.org/10.1007/978-1-4613-1755-5_5

[2] OIE-World Organization for Animal Health (2015) Manual of Diagnostic Tests and Vaccines for Terrestrial Animals: Chapter 2.01.13 Rabies (Version Adopted in May 2013).

http://www.oie.int/manual-of-diagnostic-tests-and-vaccines-for-terrestrial-animals/

[3] World Health Organization (WHO) (2015) WHO Expert Consultation on Rabies. WHO Press, Geneva. http://www.who.int/rabies/home_diagnosis/en

[4] Everard, C.O.R., James, A.C. and DaBreo, S. (1979) Ten Years of Rabies Surveillance in Grenada. Bulletin of the Pan American Health Organization, 13, 342-353.

[5] Everard, C.O.R. and Everard, J.D. (1992) Mongoose Rabies in the Caribbean. Annals of the New York Academy of Sciences, 653, 356-366. http://dx.doi.org/10.1111/j.1749-6632.1992.tb19662.x

[6] Jonkers, A.H., Alexis, F. and Loregnard, R. (1969) Mongoose Rabies in Grenada. West Indian Medical Journal, 18, 167-170.

[7] Zieger, U., Marston, D.A., Sharma, R., Chikweto, A., Tiwari, K., Sayyid, M., Louison, B., Goharrriz, K., Breed, A.C., Werling, D., Fooks, A.R. and Horton, D.L. (2014) The Phylogeography of Rabies in Grenada, West Indies, and Prospects for Control. PLoS Neglected Tropical Diseases, 8, Article ID: e3251. http://dx.doi.org/10.1371/journal.pntd.0003251

[8] Umoh, J.U. and Blenden, D.C. (1982) The Dissemination of Rabies Virus into Cranial Nerves and Other Tissues of Experimentally Infected Goats and Dogs, and Naturally Infected Skunks. International Journal of Zoonoses, 9, 1-11.

[9] Rupprecht, C.E., Hanlon, C.A. and Hemachudha, T. (2002) Rabies Re-Examined. Lancet, 2, 327-343. http://dx.doi.org/10.1016/S1473-3099(02)00287-6

[10] Trimarchi, C.V. and Nadin-Davis, S.A. (2007) Diagnostic Evaluation. In: Jackson, A.C. andWunner, W.H., Eds., 2nd Edition, Rabies, Academic Press, San Diego, 411-470. http://dx.doi.org/10.1016/B978-012369366-2/50012-9

[11] Blenden, D.C., Bell, J.F., Tsao, A.T. and Umoh, J.U. (1983) Immunofluorescent Examination of the Skin of RabiesInfected Animals as a Means of Early Detection of Rabies Virus Antigen. Journal of Clinical Microbiology, 18, 631636.

[12] Dacheux, L., Reynes, J.M., Buchy, P., Sivuth, O., Diop, B.M., Rousset, D., Rathat, C., Jolly, N., Dufourcq, J.B., Nareth, C., Diop, S., Iehle, C., Rajerison, R., Sadorge, C. and Bourhy, H. (2008) A Reliable Diagnosis of Human Rabies Based on Analysis of Skin Biopsy Specimens. Clinical Infectious Diseases, 47, 1410-1417. http://dx.doi.org/10.1086/592969

[13] Wacharapluesadee, S., Tepsumethanon, V., Supavonwong, P., Kaewpom, T., Intarut, N. and Hemachudha, T. (2012) Detection of Rabies Viral RNA by TaqMan Real-Time RT-PCR Using Non-Neural Specimens from Dogs Infected with Rabies Virus. Journal of Virological Methods, 184, 109-112. http://dx.doi.org/10.1016/j.jviromet.2012.05.013

[14] Bansal, K., Singh, C.K.K., Ramneek, Sandhu, B.S., Deka, D., Dandale, M. and Sood, N.K. (2012) Antemortem Diagnosis of Rabies from Skin: Comparison of Nested RT-PCR with TaqMan Real Time PCR. Brazilian Journal of Veterinary Pathology, 5, 116-119.

[15] Bansal, K., Singh, C.K., Sandhu, B.S., Sood, N.K. and Dandale, M. (2014) Antemortem Diagnosis of Rabies from Skin by TaqMan Real Time PCR. Indian Journal of Animal Research, 48, 597-600. http://dx.doi.org/10.5958/0976-0555.2014.00038.7

[16] Kaw, A., Singh, C.K., Ramneek, Deka, D., Sandhu, B.S., Awahan, S. and Sood, N.K. (2014). Comparison of Hair Follicles and Skin for Ante Mortem Detection of Rabies: A Molecular Approach. Indian Journal of Public Health Research and Development, 5, 165-169. http://dx.doi.org/10.5958/0976-5506.2014.00296.4

[17] Bryceson, A.D.M., Greenwood, B.M., Warrell, D.A., Davidson, N.M., Pope, H.M., Lawrie, J.H, Barnes, H.J., Ballie, W.E. and Wilcox, G.E. (1975) Demonstration during Life of Rabies Antigen in Humans. Journal of Infectious Diseases, 131, 71-74. http://dx.doi.org/10.1093/infdis/131.1.71

[18] Crepin, P., Audry, L., Rotivel, Y., Gacoin, A., Caroff, C. and Bourhy, H. (1998) Intravitam Diagnosis of Human Rabies by PCR Using Saliva and Cerebrospinal Fluid. Journal of Clinical Microbiology, 36, 1117-1121. 
[19] Warrel, M.J., Looareesuwan, S., Manatsathit, S., White, N.J., Phuapradit, P., Vejjajiva, A., Hoke, C.H., Burke, D.S. and Warrell, D.A. (1988) Rapid Diagnosis of Rabies and Post-Vaccinalencephalitides. Clinical and Experimental Immunology, 71, 229-234.

[20] Smith, W.B., Blenden, D.C., Fuh, T.H. and Hiler, L. (1972) Diagnosis of Rabies by Immunofluorescent Staining of Frozen Sections of Skin. Journal of the American Veterinary Medical Association, 161, 1495-1501.

[21] Brito, M.G., Chamone, T.L., da Silva, F.J., Wada, M.Y., de Miranda, A.B., Castilho, J.G., Carrieri, M.L., Kotait, I. and Lemos, F.L. (2011) Antemortem Diagnosis of Human Rabies in a Veterinarian Infected When Handling a Herbivore in Minas Gerais, Brazil. Revista do Instituto de Medicina Tropical de Sao Paulo, 53, 39-44. http://dx.doi.org/10.1590/s0036-46652011000100007

[22] Macedo, C.I., Carnieli Jr., P., Brandao, P.E., Travassos da Rosa, E.S., de Novaes-Oliveira, R., Galera-Castilho, J., Medeiros, R., Rocha-Machado, R., de Olivera, R.C., Carrieri, M.L. and Kotait, I. (2006) Diagnosis of Human Rabies Cases by Polymerase Chain Reaction of Neck-Skin Samples. The Brazilian Journal of Infectious Diseases, 10, 341-345. http://dx.doi.org/10.1590/S1413-86702006000500008

[23] Smith, J., McElhinney, L., Parsons, G., Brink, N., Doherty, T., Agranoff, D., Miranda, M.E. and Fooks, A.R. (2003) Case Report: Rapid Ante-Mortem Diagnosis of a Human Case of Rabies Imported into the UK from the Philippines. Journal of Medical Virology, 69, 150-155. http://dx.doi.org/10.1002/jmv.10253

[24] Blenden, D.C., Frost, J.W., Wachendoerfer, G. and Dorsey, C. (1980) Identification of Rabies Virus Antigen in the Skin of Foxes. Zentralblatt für Veterinärmedizin Reihe B, 27, 698-704. http://dx.doi.org/10.1111/j.1439-0450.1980.tb02024.x

[25] Blenden, D.C. (1981) Rabies in a Litter of Skunks Predicted and Diagnosed by Skin Biopsy. Journal of the American Veterinary Medical Association, 179, 789-791.

[26] Ciuchini, F., Pestalozza, S., Buonavoglia, C. and Irsara, A. (1984) Evaluation of Immunofluorescence Staining of Skin for the Diagnosis of Rabies. Zentralblatt für Veterinärmedizin Reihe B, 31, 32-35. http://dx.doi.org/10.1111/j.1439-0450.1984.tb01277.x

[27] Wacharapluesadee, S. and Hemachudha, T. (2010) Ante- and Post-Mortem Diagnosis of Rabies Using Nucleic Acid Amplification Tests. Expert Review of Molecular Diagnostics, 10, 207-218. http://dx.doi.org/10.1586/erm.09.85 